\title{
Customers' Perceived Risk and Trust in Using Mobile Money Services- an Empirical Study of Ghana
}

\author{
Ibn Kailan Abdul-Hamid, University of Professional Studies, Accra, Ghana \\ Aijaz A. Shaikh, University of Jyväskylä, Jyväskylä, Finland \\ Henry Boateng, University of Technology Sydney, Ultimo, Australia \\ Robert E. Hinson, University of Ghana and University of the Free State Business School, Accra, Ghana
}

\begin{abstract}
Although mobile money (MM) has been explored in the existing literature, the roles of trust and risk in MM use have received little attention from researchers. Furthermore, many of the existing studies have treated these constructs as unidimensional. The extant literature also shows that perceived risk has received little attention from researchers who have conducted studies on MM. Thus, the objective of this study is to examine the roles of trust and perceived risk in customers' intent to adopt MM services in Ghana. Both trust and perceived risk were broken down into various dimensions. The study involved 671 respondents who were selected via an intercept approach and an online survey. Structural equation modelling was used to test the study's hypotheses. The findings show that perceived risk is negatively associated with customers' intent to use MM services and economy-based trust. Trust in service providers and economy-based trust are positively associated with customers' intent to use MM services. The implications of the findings are provided in the latter part of this study.
\end{abstract}

\section{KEYWORDS}

Ghana, Mobile Money, Mobile Networks, Mobile Payments, Perceived Risk, Trust

\section{INTRODUCTION}

Mobile money (MM), also referred to as branchless banking, is a banking and payment tool that uses portable devices to allow individuals to access and complete financial transactions, such as funds transfers and payment of utility bills. In light of the exponential growth of cell phone coverage and usage (Gichuki \& Mulu-Mutuku, 2018), MM services are seen as a likely solution to financial exclusion on the African continent (Tchouassi, 2012), including in Ghana. Increasing cell phone diffusion in Ghana has led to a remarkable growth in the adoption and usage of MM services. For example, in 2015, there were 13.1 million users of MM services; by 2017, this figure had jumped to 23.95 million - a growth rate of more than $83 \%$ in two years (www.bog.gov.gh). However, while this increase in the usage of MM services looks promising, the total population in Ghana accessing and using the MM services now stands at about $50 \%$. The remaining $50 \%$ of the Ghanaian population is still outside the MM services net; therefore, the industry, regulators and academics need to determine 
how to increase MM usage and financial inclusion for the remotely located and previously unbanked segment of the population.

Online transactions are associated with customer concerns about consumer trust and perceptions of risk linked to remotely executed payment services such as MM (PWC, 2016). Prior researchers (e.g., Yang et al., 2015; Ratnasingam et al., 2005) have considered the factors 'trust' and 'risk' as central to the adoption and use of electronic payment systems and electronic commerce. Some researchers (e.g., Im et al., 2008) have also noted that the technology adoption and usage literature has often neglected the role of perceived risk in technology use, and there is a need to further investigate this issue in relation to MM use. The few existing studies in Ghana treated trust and risk as unidimensional constructs (see for example Tobbin \& Kuwornu, 2011), but the existing literature (e.g., Ball et al., 2016) argued that, trust and risk should be considered as multidimensional constructs. Moreover, the association between risk and trust issues and MM service use intent in Ghana has rarely been examined. Against this backdrop, this study first contributes to the existing literature on MM use intent in a developing country context by treating trust and risk as multidimensional constructs. Second, it examines how perceived risk influences the consumer's intent to use MM services. Third, it explores economy-based trust and intent to use the MM service nexus. Fourth, it examines trust in the MM service provider and intent to engage in a MM service relationship.

The rest of the paper is organized as follows. After a review of the theoretical background and existing literature, the research model and study hypotheses are elaborated, followed by an account of sampling design, measures, descriptive statistics, model measurement and structural equation modelling. The paper concludes with implications, limitations and directions for future research.

\section{THEORETICAL BACKGROUND AND LITERATURE REVIEW}

\section{Services}

MM involves the use of mobile phones to access financial services remotely that have typically been provided over a counter (Mothobi \& Grzybowski, 2017). MM services largely include transfers and payments. MM is also referred to as cell phone banking, over-the-counter banking, agent banking and branchless banking (Diniz et al., 2012).

The weaknesses of traditional and other electronic banking channels (ATMs and online banking) in fulfilling customers' financial needs and requirements due to limited availability, week internet connectivity and other access issues may be the reason for the increasing popularity of MM services.

MM services are a novel way of accessing and conducting low-cost financial transactions. Unlike other digital banking channels, MM services operate at the intersection of finance and telecom and involve a diverse set of stakeholders with competing players from various fields (Donovan, 2012). Among these stakeholders or actors, MM agents (individuals or firms who operate mobile money services) are at the frontline of MM service deployment and play a decisive role in the success of MM services in Ghana and elsewhere.

\section{Trust and Risk in Digital Services}

It is widely believed (e.g., Safeena et al., 2018) that 'trust' and 'risk' occupy significant positions in e-business services (including e-commerce). This is perhaps because of the uncertainty and risk involved in online transactions conducted remotely using portable devices, which are prone to hacking, loss and misuse (Shaikh et al., 2018). Trust reflects a willingness to be vulnerable based on the positive expectation of another party's future behaviour (Kim et al., 2018). With regard to MM services in a developing country, trust refers to the consumer's belief that MM services will be costand time-effective and that service providers will safeguard their clients' money and information. As a third-party provider, such as an agent, normally delivers MM services, the role of trust in consumer intent to use MM services relates directly to the customer's trust in that agent. 
Trust is crucial in economic transactions because it may reduce the risk of falling victim to opportunistic behaviour, and lack of trust is among the main reasons consumers decide not to engage with MM and other similar services (Chauhan, 2015). Scholars (e.g., Ball et al., 2016; Gefen et al., 2003) have suggested that trust is a multidimensional concept. Trust is associated with perceived risk, and it can be argued that lack of trust increases perceived risk (Kim \& Peterson, 2017). In the mobile banking context, risk or perceived risk is defined as the exposure to danger that arises from the purchase of a banking product or service, such as m-banking (Shaikh et al., 2018). In this study, we have defined perceived risk as the amount of risk an underbanked consumer sees when using MM services in a developing country. As risk can be difficult to measure objectively, the literature focuses on users' risk perceptions. When the perceived risk in any transaction is high, consumers may decide not to engage in that transaction or may terminate the ongoing exchange relationship (Al-Gahtani, 2011). In the present context, then, it can be argued that perceived risk may increase consumers' unwillingness to use MM services.

\section{Technology Adoption and Usage Models}

Many studies have deployed theories to explain technology utilization; prominent among these are the unified theory of acceptance and use of technology (UTAUT) (Venkatesh et al., 2003), diffusion of innovation theory (Rogers, 1995), the theory of planned behaviour (Ajzen, 1991), the technology acceptance model (TAM) (Davis et al., 1989) and the theory of reasoned action (Fishbein \& Ajzen, 1975). Application of these theories has yielded varying results (Venkatesh et al., 2003). For example, Rogers's diffusion of innovation theory identifies five essential features that drive user adoption of an innovation: complexity, relative advantage; trialability, observability and compatibility (Rogers, 1995). The theories of planned behaviour and reasoned action (Ajzen, 1991) have shown that technology adoption can be determined by perceived behavioural control, as well as by subjective norms and attitudes.

Davis et al. (1989) developed the TAM to explain user adoption. Davis et al. (1989) noted that the perceived usefulness and perceived ease of use of a given technology determine user attitudes toward it, and a number of other studies have provided empirical support for this view. For example, Taylor and Todd (1995) reported that users exhibit positive attitudes when they perceive that a technology is easy to use. Following the TAM model, researchers have identified many other factors that drive user adoption of technology. Venkatesh et al. (2003) attempted to integrate all of these factors in their UTAUT framework, which integrates performance expectancy and effort expectancy with perceived usefulness and ease of use. There is evidence that this model is robust to the extent that it has been found to explain $70 \%$ of the variance in technology usage intentions (Wu et al., 2008). However, these dominant models rarely address issues of trust and risk that are of concern to many users of technology-based services, especially in the financial services sector (Yang et al., 2015). The present study seeks to bridge that gap by examining customer intent to use mobile services in terms of customer trust and perceived risk.

\section{Research Model and Hypothesis Development}

The various dimensions of risk seem likely to differ in their influence, contributing to varying degrees to the effect of overall perceived risk on intent to use MM services. As conceptualized here, perceived risk is understood to involve concerns about economic, functional, security, privacy, time, service, psychological and social risk. A positive association is hypothesized to exist between trust and consumer intent to use MM, two components of trust: economy-based and service provider-based. As perceived risk is likely to reduce trust in mobile-based payments (Yang et al., 2015), it is further hypothesized that perceived risk is negatively associated with both economy-based trust and service provider-based trust. Figure 1 depicts the research model developed. 


\section{TRUST, PERCEIVED RISK AND INTENT TO USE MM SERVICES}

Trust and perceived risk are prevalent concepts that influence behavioural intentions to use MM services. The management of money (physical or electronic) is expected to produce some benefits to its owners. Accordingly, the use of MM services is expected to deliver benefits to as well as create fear among users who are largely either underbanked or unbanked. For example, a user's perception that the use of a MM service may expose him or her to the loss of money could influence the adoption of MM services. MM users may not be able to predict the outcome of such decisions accurately, and those outcomes may prove undesirable (Yang et al., 2015). Moreover, because of the nature of MM transactions, they usually lack the assurance provided in traditional settings, such as in the form of receipts, making it more difficult for consumers to seek compensation when transaction errors occur. Based on these arguments, we propose the following hypothesis:

H1a: Economic risk influences the perceived risk of MM services.

A functional risk is a probability that a service may not be performed as expected (Yang et al., 2015). Thus, functional risk relates to transaction-specific uncertainty about MM services (Yousafzai et al., 2003; Martins et al., 2014). A consumer's perception of functional risk is significant, as it affects the decision to use MM services. Accordingly, a consumer's concern about the stability and reliability of an MM service influences the degree of perceived risk (Yang et al., 2015). Thus, we propose the following hypothesis:

H1b: Functional risk influences the perceived risk of MM services.

Security risk relates to threats that produce situations, conditions or events with the potential to cause economic hardship to data or network resources in the form of damage, leaks, alteration of data, denial of service, fraud, waste or abuse (Nofer, 2015). MM customers may fear identity theft, as there is evidence that customers using electronic platforms believe they are highly vulnerable to such theft (Hille et al., 2015). In addition, perceived threats such as network and data transaction attacks and unauthorized access to an account by means of false or defective authentication create security issues (Nofer, 2015). Some studies have predicted that the greatest challenge for MM services in winning customers' trust is in relation to security issues (Jang-Jaccard \& Nepal, 2014). We propose the following hypothesis:

H1c: Security risk influences the perceived risk of MM services.

Perceived privacy refers to a consumer's preference to control who is present during a market transaction and the diffusion of information associated with such transactions to persons who were not present (Ortiz et al., 2018). MM customers may be concerned that a third party could steal their information (personal or transactional) during MM transactions. Perceived privacy has become especially critical since customers can now link their MM accounts to their bank accounts. These forms of risk are known to have negatively impacted electronic banking services (Sum Chau \& Ngai, 2010) and are therefore likely to have a negative effect on intent to use MM services. Some studies have predicted that the greatest challenge for MM services will be winning customers' trust in relation to privacy issues (Aboobucker, \& Bao, 2018). Based on the above, we propose the following hypothesis:

H1d: Privacy risk influences the perceived risk of MM services. 
One benefit of MM is that completing a transaction requires little time (Omwansa et al., 2013). However, many potential users of MM services may also perceive this benefit as a risk. According to Yang et al. (2015), time risk - that is, inconvenience and loss of time due to delays in receiving a payment or transferring money-is negatively associated with mobile payment transactions. This form of risk may be a consequence of functional risk. Network failure is very common among telecommunications firms in Ghana, which can cause undue delays in sending and receiving money. Consequently, consumers who are very time-oriented and concerned about the risk of 'wasting time' are less likely to use MM services (Featherman \& Pavlou, 2003). Thus, we propose the following hypothesis:

H1e: Time risk influences the perceived risk of MM services.

MM users may view MM services as risky for a number of reasons. For example, a potential user may be uncertain whether or not a service will be performed as expected, which could create financial, functional and even physical risk (Carnevale et al., 2018). Accordingly, perceived service risk negatively affects consumers' perceived service value and thus lowers purchase likelihood (Chang \& Hsiao, 2008; Carnevale et al., 2018). We propose the following hypothesis:

H1f: Service risk influences the perceived risk of MM services.

Psychological risk refers to the chance that a user will experience negative emotions like fear, frustration, pressure or anxiety from the use of MM services (Ortiz et al., 2018). The potential experience of fear and anxiety in sending or receiving money may affect users' decisions to use MM services.

H1g: Psychological risk influences the perceived risk of MM services.

A further relevant dimension that may affect intent to use MM services is social risk. Social risk refers to the possibility that the use of MM may prompt disapproval from one's friends, family or workgroup. Depending on how MM is viewed, using it may enhance or diminish one's social standing. It may be that people's perceptions of MM affect their views of its users, or not using MM may have certain social connotations. In both attitudinal and technology acceptance research, this 'reference group effect' is known to play a significant role risk perception (Lee \& Lemyre, 2009). It follows that perceived social risks may affect customers' willingness to use MM services. We propose the following hypothesis:

H1h: Social risk influences the perceived risk of MM services.

Trust involves a positive expectation regarding services in risky situations (Das \& Teng, 2012). An economy-based trust is a form of trust based on economic benefits (Chai \& Kim, 2010). The perceptions of MM users about the time- and cost-saving benefits and economical use of MM services relate to their economy-based trust in such services (Chai \& Kim, 2010). When customers become conscious of MM service charges or costs that exceed their gain from the MM service they turn to lose trust in the service. Consequently, perceived risk of using MM services could affect the economy-based trust. We propose the following hypothesis:

$\mathrm{H}$ 2: Perceived risk influences economy-based trust. 
Perceived risk may be regarded as uncertainty about the possible negative effects of using MM services. Accordingly, perceived risk is a blend of uncertainty and the seriousness of MM service outcomes (Featherman \& Pavlou, 2003). Because the outcomes of MM service decisions can be uncertain, the perceived risk of MM services may negatively influence customers' intent to use MM services (Lopez-Nicolas \& Molina-Castillo, 2008). Similarly, Park et al. (2005) found a negative relationship between perceived risk and intent to purchase online. Given the lack of customer trust in mobile payment systems and the perceived risk associated with MM systems (Yang et al., 2015), it is logical to argue that perceived risk influences consumer intent to use MM services. Risk is also associated with trust (Pavlou et al., 2007) and serves to undermine customer trust in mobile payment systems (Yang et al., 2015). MM is efficient and cost-effective in comparison to many other forms of bank or payment services, but perceived risk may still affect a consumer's intent to use MM services (Bauer et al., 2005). Therefore, we hypothesize that:

H3: Perceived risk influences the customer's intent to use MM services.

Perceived risk and trust are known to influence consumer behavioural intentions (Martins et al., 2014; Namahoot \& Laohavichien, 2018). Thus, a consumer's perception of risk influences his or her behaviour toward MM services (Bauer et al., 2005). Customers of MM services believe that MM services possess several risk elements (time risk, security risk, privacy risk, etc.) (Namahoot \& Laohavichien, 2018). Consumers of MM services may attempt to minimize perceived risk while maximizing the services' utility (Bauer et al., 2005). Similarly, Liebana-Cabanillas et al. (2013), found that perceived risk has a positive influence on trust in MM services. Thus, we propose the following hypothesis:

H4: Perceived risk influences trust in MM service providers.

Trust plays a central role in MM utilization (Tobbin \& Kuwornu, 2011). For present purposes, trust is understood to relate to both economic and service-provider factors, essential aspects of customer decision-making in an electronic environment (Chai \& Kim, 2010). As such, trust affects the relationship between risk and MM service use intent. Since trust is related to positive customer attitude (Song \& Zahedi, 2002), it is likely to favourably influence MM transaction intent; conversely, lack of trust is likely to adversely affect usage of MM services. According to Gefen et al. (2003), customers make rational assessments in electronic environments to ensure that they obtain value for their money. There is also evidence that customers do not want to waste time in their business transactions and therefore favour electronic commerce, which reduces transaction time (Kuisma et al., 2007). A study by, Chai and Kim (2010) shows that economy-based trust influences consumer behaviour, consequently, we also argue that a consumer's level of economic trust is likely to affect consumer behaviour in relationship to MM services usage. As customers prefer to deal with vendors they can trust (Pavlou et al., 2007), it seems likely that trust in MM service providers (telecoms, banks and agents) will affect customer intent to use MM services. On that basis, we propose the following hypotheses:

H5: Economy-based trust influences customer intent to use MM services.

H6: Trust in MM service providers influences customer intent to use MM services.

\section{Measures}

All the items used for measuring the constructs were adapted from the existing literature. Specifically, all items on customers' intent to use MM services were adapted from Yang et al. (2015). Similarly, items measuring the dimensions of perceived risk (economic, functional, security, privacy, time, 
service, psychological and social risk) were adapted from Yang et al. (2015) and from Featherman and Pavlou (2003). The items measuring economy-based trust and trust in the service provider were adapted from Chai and Kim (2010). For clarity, all items were measured on a five-point Likert scale ( $1=$ strongly disagree, $2=$ disagree, $3=$ neutral, $4=$ agree and $5=$ strongly agree). Because all of the items measuring perceived risk were negative in form, coding was reversed during the analysis. However, coding for service-provider trust and economy-based trust and intent to use MM remained the same because the items were positive in form. The questionnaire items are attached as an appendix.

\section{RESEARCH METHODOLOGY}

To test the model and the hypotheses, we used a survey-based research design to collect quantitative data from a large number of respondents. The questionnaire developed on the basis of the proposed model was produced in English and was distributed only to respondents who could read and understand it sufficiently well to respond. The questionnaire was pre-tested in January and February 2017 with the assistance of graduate students from an executive master of business administration course and a master of a philosophy course at the University of Ghana Business School. A revised version of the data collection instrument was produced based on insights from the pre-testing. That revised version was used to collect the study data across Ghana from April to June 2017. The target respondents were users of MM services-for example, people who either transfer or receive money using these services. The respondents were drawn from all ten regions of Ghana (see Table 1). To speed up data collection and to capture a larger portion of the target population, graduate and undergraduate students were trained as research assistants.

Data collection involved two components. First, the intercept approach was used to collect data from respondents in the Greater Accra region. The research assistants intercepted some potential respondents while they were using MM services; others were captured after using such services. This approach to data collection has been used as a means of improving response rates (e.g., Boateng et al., 2016). The second component of data collection was an online survey, which was used to capture respondents from the remaining nine regions. Although limited access to the Internet and Internet literacy made it challenging to capture different types of respondents, the intercept approach helped to address this issue, given the cosmopolitan nature of the Greater Accra region. All of the responses were then combined and analysed together.

In all, there were 671 usable questionnaires for the final analysis. A majority of respondents (54.2\%) were male, and the remaining $45.8 \%$ were female. Most of the respondents $(83.5 \%)$ ranged in age from 18 to 27 years, and most (71.7\%) had completed a university degree. Overall, $48.7 \%$ used the MM services of MTN, and most (74.7\%) used MM services between one to five times a month. Additionally, most of the respondents (93.9\%) were Christians. There were more respondents from the Greater Accra region (33.7\%) than from other regions. As most of the respondents were unwilling to disclose their average monthly income, this information was not captured in the final analysis. Table 1 includes details of all demographic data.

We checked for common method variance (CMV) before testing our hypotheses using Harman's one-test factor (Podsakoff et al. 2003). This was done by entering all the variables into an exploratory factor analysis (EFA). From the findings of the EFA, more than one factor emerges from a factor analysis. Additionally, when all our measurement items were forced to load onto a single factor, it did not account for $50 \%$ of the variance. Consequently, there was no serious concerns of CMV.

\section{Results}

We used the partial least squares structural equation modelling (PLS-SEM) approach to assess our measurement model and the hypotheses of this study by running SmartPLS 3.0 (Ringle, Wende, \& Becker, 2015). PLS is appropriate for testing hierarchical latent variable models, hierarchical component models or higher-order constructs. Compared to covariance-based structural equation 
Table 1. Demographic characteristics

\begin{tabular}{|c|c|c|c|}
\hline \multicolumn{2}{|c|}{ Details } & \multirow{2}{*}{$\frac{\text { Frequency }}{364}$} & \multirow{2}{*}{$\frac{\text { Percent }}{54.2}$} \\
\hline Gender & Male & & \\
\hline & Female & 307 & 45.8 \\
\hline \multirow[t]{4}{*}{ Educational level } & HND & 31 & 4.6 \\
\hline & Degree & 481 & 71.7 \\
\hline & Postgraduate & 52 & 7.7 \\
\hline & Other & 107 & 15.9 \\
\hline \multirow[t]{5}{*}{ Age } & $18-27$ years & 560 & 83.5 \\
\hline & 28 - 37 years & 57 & 8.5 \\
\hline & 38 - 37 years & 27 & 4.0 \\
\hline & 48 - 57 years & 21 & 3.1 \\
\hline & 58 years and above & 6 & .9 \\
\hline \multirow[t]{3}{*}{ Network } & MTN & 327 & 48.7 \\
\hline & AirtelTigo & 202 & 30.1 \\
\hline & Vodafone & 142 & 21.1 \\
\hline \multirow{5}{*}{$\begin{array}{l}\text { The frequency of Use } \\
\text { (Month) }\end{array}$} & $1-5$ times & 501 & 74.7 \\
\hline & 6-10 times & 97 & 14.5 \\
\hline & $11-15$ times & 39 & 5.8 \\
\hline & 16-20 times & 12 & 1.8 \\
\hline & more than 20 times & 22 & 3.3 \\
\hline \multirow[t]{2}{*}{ Religion } & Christian & 630 & 93.9 \\
\hline & Moslem & 36 & 5.4 \\
\hline \multirow[t]{11}{*}{ Region } & Greater Accra & 226 & 33.7 \\
\hline & Central Region & 83 & 12.4 \\
\hline & Eastern Region & 117 & 17.4 \\
\hline & Western Region & 23 & 3.4 \\
\hline & Volta Region & 87 & 13.0 \\
\hline & Ashanti Region & 79 & 11.8 \\
\hline & Brong-Ahafo Region & 19 & 2.8 \\
\hline & Northern Region & 15 & 2.2 \\
\hline & Upper East Region & 15 & 2.2 \\
\hline & Upper West Region & 7 & 1.0 \\
\hline & Total & 671 & 100.0 \\
\hline
\end{tabular}

modelling, PLS-SEM is designed to handle observable lower-order components (LOCs) and unobservable higher order components (HOCs) to reduce model complexity and this makes it more theoretically parsimonious (Lohmöller, 1989). 


\section{Measurement Model Assessment}

The assessment of the measurement models is the first step in any SEM process, as it ensures that statements (unobserved variables) are actually measured constructs (observed variables). We assessed our measurement model using three main criteria: convergent validity, reliability and discriminant validity, following the suggestion of Hair et al. (2014).

Convergent validity of the items was assessed by outer loadings and average variance extracted (AVE). All outer loadings for items are above 0.6, which is above the minimum threshold value of 0.6 Bagozzi and Yi (1988) suggested. The outer loadings therefore, provided the support for convergent validity (see Hair et al., 2014). The AVE values of 0.599 to 0.814 are well above the minimum required level of 0.50, as Fornell and Larcker (1981) suggested, thus also demonstrating the convergent validity for all constructs. Composite reliability (CR) measures were all higher than the 0.7 thresholds (Table 1) of Chin (2010). That is, among measurement models, the reliability measure of constructs in this study were above the acceptable satisfactory levels (see Table 2).

Discriminant validity was evaluated based on the Fornell-Lacker criterion and cross-loadings. The Fornell-Larcker criterion Fornell and Larcker (1981) suggested states that the square root of the AVE should be greater than the correlation shared between the construct and the other constructs (see Table 3).

\section{Test of the Hierarchical Factor Structure}

The present study views perceived risk as a second-order factor. PLS was, therefore, suitable for this analysis; perceived risk was treated as an HOC with its LOCs economic risk, functional risk, privacy risk, psychological risk, security risk, service risk and social risk. The findings show that the secondorder and first-order factor loadings are high and statistically significant. Economic risk $(\gamma=.676$; $\mathrm{p}<.001)$, functional risk $(\gamma=.642 ; \mathrm{p}<.001)$, privacy risk $(\gamma=.737 ; \mathrm{p}<.001)$, psychological risk $(\gamma=.620 ; \mathrm{p}<.001)$, security risk $(\gamma=.789 ; \mathrm{p}<.001)$, service risk $(\gamma=.601 ; \mathrm{p}<.001)$ and social risk $(\gamma=.372 ; \mathrm{p}<.001)$ exhibited significant coefficients in support of H1a, H1b, H1c, H1d, H1e, $\mathrm{H} 1 \mathrm{f}, \mathrm{H} 1 \mathrm{~g}$ and $\mathrm{H} 1 \mathrm{~h}$. These results provide strong support for the customer perceived risk scale as a second-order construct.

\section{Structural Model Assessment}

After validating the measurement model, we assessed our structural model, which involved testing our hypothesis. Of the five hypotheses, one (1) was not supported; the relationship between perceived risk and economy-based trust was not significant $(\beta=0.021 ; p=0.605)$. However, the relationship between perceived risk and customer intent to use MM services was significant $(\beta=0.065 ; \mathrm{p}=$ 0.016). Additionally, there was a significant relationship between perceived risk and trust in the service provider $(\beta=0.159 ; \mathrm{p}=0.000)$. The structural paths showed a significant relationship between economy-based trust and customer intent to use MM services $(\beta=0.441 ; \mathrm{p}=0.000)$ and between trust in the service provider and customer intent to use MM services $(\beta=0.266 ; p=0.000)$, as seen in Table 4. Figure 2 shows the structural model.

As can be observed from the model (Figure 2 and Table 4), there were three outcome constructs with the following R-squares $\left(\mathrm{R}^{2}\right)$ : customer intent to use MM services (.371), economy-based trust $(.000)$ and trust in the service provider (.025). These results indicate that perceived risk does not explain economy-based trust. Also, the findings show that perceived risk provides a moderate explanation (37.1\%) of trust in customer intent to use MM services. However perceived risk provides a weak explanation $(2.5 \%)$ of the variance in trust in the service provider. 
Table 2. Summary results for measurement model quality

\begin{tabular}{|c|c|c|c|c|}
\hline Construct & Items & Loadings & AVE & $\mathbf{C R}$ \\
\hline \multirow[t]{4}{*}{ Economic risk } & & & 0.554 & 0.788 \\
\hline & ERK1 & 0.707 & & \\
\hline & ERK2 & 0.77 & & \\
\hline & ERK3 & 0.755 & & \\
\hline \multirow[t]{4}{*}{ Functional risk } & & & 0.627 & 0.834 \\
\hline & FRK1 & 0.742 & & \\
\hline & FRK2 & 0.814 & & \\
\hline & FRK3 & 0.817 & & \\
\hline \multirow[t]{5}{*}{ Security risk } & & & 0.643 & 0.878 \\
\hline & SRK1 & 0.79 & & \\
\hline & SRK2 & 0.85 & & \\
\hline & SRK3 & 0.826 & & \\
\hline & SRK4 & 0.737 & & \\
\hline \multirow[t]{4}{*}{ Privacy risk } & & & 0.708 & 0.879 \\
\hline & PRK1 & 0.852 & & \\
\hline & PRK2 & 0.87 & & \\
\hline & PRK3 & 0.801 & & \\
\hline \multirow[t]{4}{*}{ Time risk } & & & 0.704 & 0.877 \\
\hline & TMK1 & 0.816 & & \\
\hline & TMK2 & 0.866 & & \\
\hline & TMK3 & 0.834 & & \\
\hline \multirow[t]{4}{*}{ Service risk } & & & 0.683 & 0.866 \\
\hline & SK1 & 0.847 & & \\
\hline & SK2 & 0.873 & & \\
\hline & SK3 & 0.755 & & \\
\hline \multirow[t]{4}{*}{ Psychological risk } & & & 0.625 & 0.833 \\
\hline & PK1 & 0.75 & & \\
\hline & PK2 & 0.798 & & \\
\hline & PK3 & 0.822 & & \\
\hline \multirow[t]{4}{*}{ Social risk } & & & 0.599 & 0.817 \\
\hline & SKk1 & 0.845 & & \\
\hline & SKk2 & 0.781 & & \\
\hline & SKk3 & 0.689 & & \\
\hline \multirow[t]{4}{*}{ Economy-based trust } & & & 0.726 & 0.888 \\
\hline & ET1 & 0.838 & & \\
\hline & ET2 & 0.85 & & \\
\hline & ET3 & 0.867 & & \\
\hline \multirow[t]{4}{*}{ Trust in service providers } & & & 0.744 & 0.897 \\
\hline & TP1 & 0.853 & & \\
\hline & TP2 & 0.896 & & \\
\hline & TP3 & 0.837 & & \\
\hline \multirow[t]{4}{*}{$\begin{array}{c}\text { Intentions to use mobile } \\
\text { money services }\end{array}$} & & & 0.814 & 0.929 \\
\hline & IUM1 & 0.904 & & \\
\hline & IUM2 & 0.928 & & \\
\hline & IUM3 & 0.874 & & \\
\hline
\end{tabular}

\section{DISCUSSION AND CONCLUSIONS}

This study investigated the various components of trust and risk that affect customer intent to use MM services in Ghana. The study had six main hypotheses with eight sub-hypotheses. The findings 
Table 3. Construct correlation matrix

\begin{tabular}{|l|c|c|c|c|c|c|c|c|c|c|c|}
\hline & $\mathbf{1}$ & $\mathbf{2}$ & $\mathbf{3}$ & $\mathbf{4}$ & $\mathbf{5}$ & $\mathbf{6}$ & $\mathbf{7}$ & $\mathbf{8}$ & $\mathbf{9}$ & $\mathbf{1 0}$ & $\mathbf{1 1}$ \\
\hline 1 Economic risk & $\mathbf{0 . 7 4 5}$ & & & & & & & & & & \\
\hline $\begin{array}{l}\text { 2 Economy-base } \\
\text { trust }\end{array}$ & 0.051 & $\mathbf{0 . 8 5 2}$ & & & & & & & & & \\
\hline 3 Functional risk & 0.429 & 0.054 & $\mathbf{0 . 7 9 2}$ & & & & & & & & \\
\hline $\begin{array}{l}\text { 4 Intention to use } \\
\text { mobile money }\end{array}$ & 0.097 & 0.550 & 0.025 & $\mathbf{0 . 9 0 2}$ & & & & & & & \\
\hline 5 Privacy risk & 0.433 & 0.043 & 0.39 & 0.036 & $\mathbf{0 . 8 4 2}$ & & & & & & \\
\hline 6 Psychological risk & 0.341 & 0.062 & 0.332 & 0.030 & 0.384 & $\mathbf{0 . 7 9 1}$ & & & & & \\
\hline 7 Security risk & 0.471 & 0.018 & 0.401 & 0.128 & 0.591 & 0.352 & $\mathbf{0 . 8 0 2}$ & & & & \\
\hline 8 Service risk & 0.309 & 0.056 & 0.296 & 0.110 & 0.279 & 0.313 & 0.324 & $\mathbf{0 . 8 2 7}$ & & & \\
\hline 9 Social risk & 0.155 & 0.048 & 0.129 & 0.118 & 0.192 & 0.222 & 0.196 & 0.177 & $\mathbf{0 . 7 7 4}$ & & \\
\hline 10 Time risk & 0.225 & 0.13 & 0.221 & 0.115 & 0.18 & 0.231 & 0.264 & 0.381 & 0.231 & $\mathbf{0 . 8 3 9}$ & \\
\hline $\begin{array}{l}\text { 11 Trust in Service } \\
\text { Provider }\end{array}$ & 0.144 & 0.404 & 0.022 & 0.454 & 0.122 & 0.038 & 0.171 & 0.104 & 0.041 & 0.107 & $\mathbf{0 . 8 6 3}$ \\
\hline
\end{tabular}

Table 4. Summary results of hypothesis testing

\begin{tabular}{|l|c|c|c|}
\hline & $\boldsymbol{\beta}$ & T Statistics & P Values \\
\hline Perceived risk -> Economy-base trust & 0.021 & 0.558 & 0.577 \\
\hline Perceived risk -> Intention to use mobile money & 0.065 & 2.513 & 0.012 \\
\hline Economy-base trust -> Intention to use mobile money & 0.441 & 13.452 & 0.001 \\
\hline Perceived risk -> Trust in Service Provider & 0.159 & 4.374 & 0.001 \\
\hline Trust in Service Provider -> Intention to use mobile money & 0.266 & 8.22 & 0.001 \\
\hline
\end{tabular}

suggest that both trust and perceived risk are multidimensional constructs. However, their importance in customers' purchase decision-making varies from one context to another, and the various dimensions of trust and perceived risk do not contribute equally to overall trust and perceived risk. The results also suggest that several other forms of trust and perceived risk are associated with MM services; apart from perceived risk, other elements within the MM service environment may also reduce customers' trust in MM service providers and in the economics of MM services.

Hypothesis H1a was supported, implying that economic risk positively impacts perceived risk of MM services. Hypothesis H1b was not supported, implying that functional risk does not positively impact perceived risk. Our study suggested that the functional risk of using MM services does not affect MM services. Hypothesis H1c was supported, implying that security risk positively impacts the perceived risk of MM services. Hypothesis H1d was not supported, implying that privacy risk does not positively impact the perceived risk of MM services. Hypothesis H1e was supported, implying that time risk positively impacts the perceived risk of MM services. Hypothesis H1f was not supported, implying that service risk does not positively impact the perceived risk of MM services. Hypothesis H1g was not supported, implying that psychological risk does not positively impact the perceived risk of MM services. Hypothesis H1h was supported, implying that social risk positively impacts the perceived risk of MM services. 


\section{Dimensions of Perceive Risk}

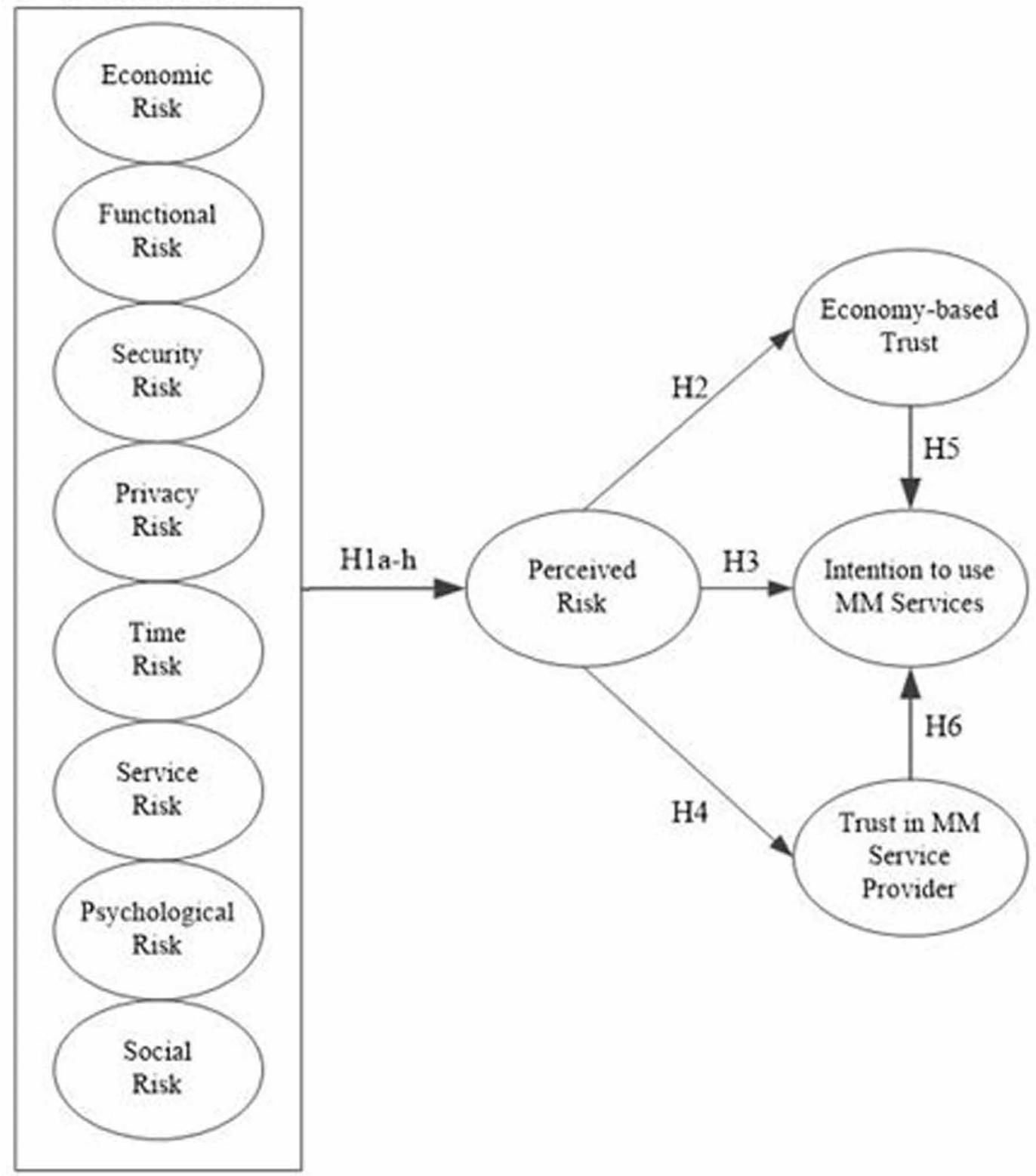

Hypothesis $\mathrm{H} 2$ was supported, implying that perceived risk positively impacts intent to use MM services. Hypothesis H3 was supported, implying that perceived risk positively impacts trust in the provider of MM services. Hypothesis H4 was not supported, implying that perceived risk does not positively impact economy-based trust of MM services. Hypothesis H5 was supported, implying that economy-based trust positively impacts intent to use MM services. Hypothesis H6 was supported, implying that trust in the service provider positively impacts intent to use MM services. 


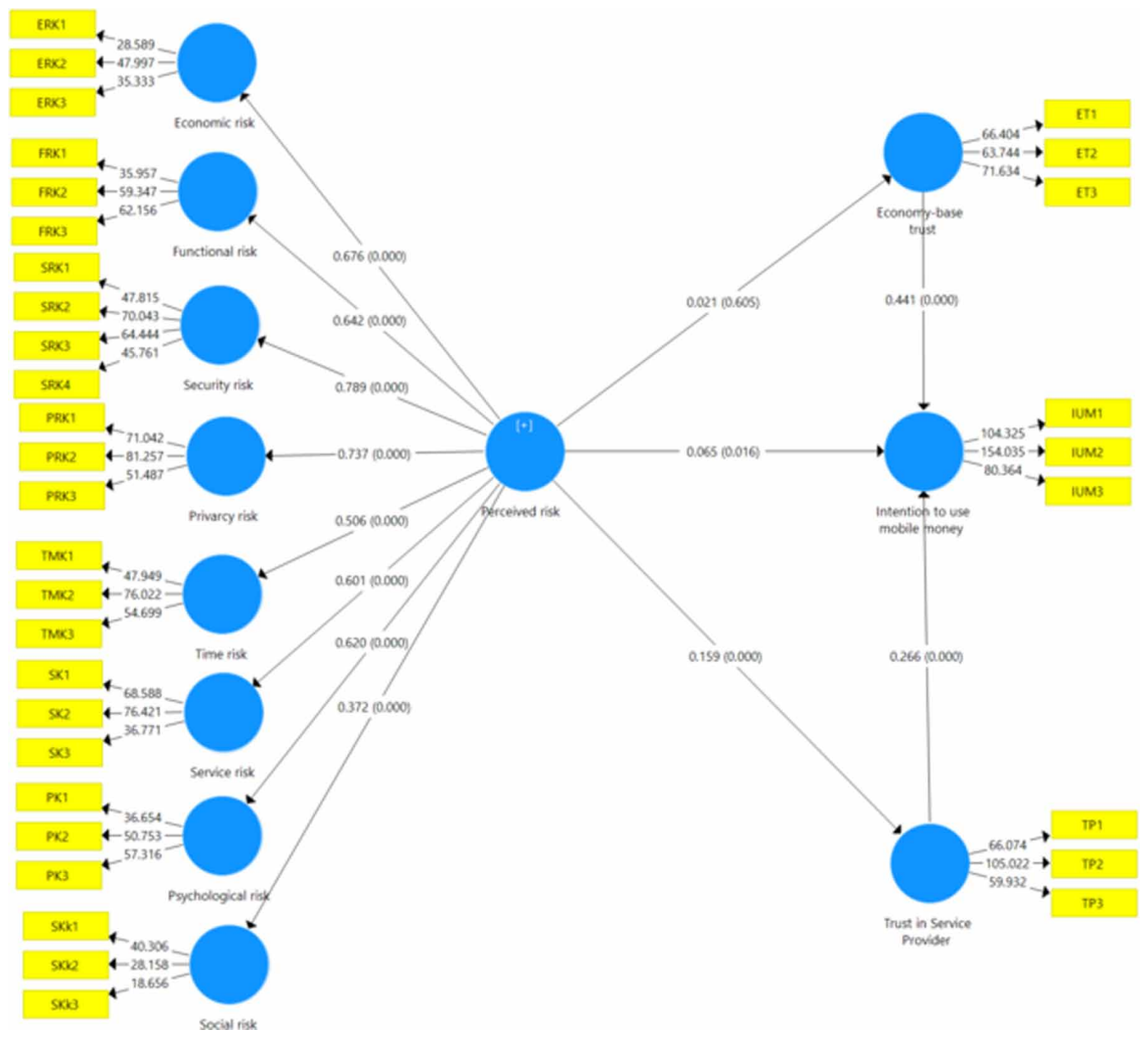

Both H5 and H6 indicated that trust affects a customer's decisions to use MM services. Previous scholars (Tobbin \& Kuwornu, 2011; Donovan, 2012) shared this observation. Accordingly, MM service providers may consider deploying strategies that create or increases customers' trust in them. Such trust may reduce the perceived risk of customers in using the MM service ( $\mathrm{Lu}$ et al., 2011; Malaquias \& Hwang, 2016).

\section{Managerial and Theoretical Implications}

For practitioners, these findings confirm that MM service providers must assure customers that they will safeguard their money and any personal information that the customers make available. Attracting more customers will also require service providers to reassure customers that MM services are time-saving and cost-effective. Although functional risk was not a significant issue, it cannot be dismissed as irrelevant. MM service providers must ensure that their services are the fastest means of sending money to others. The findings also indicate that the risk associated with MM services should be studied from a customer perspective, focusing on specific kinds of risk rather than overall risk. It follows that addressing perceived risk in MM services will also require specific strategies for dealing with the various dimensions of risk. 
Perceived risk generally makes customers anxious when they perform monetary transactions, reducing the likelihood that they will use MM services. Perceived risk also relates to the customer's trust in service providers. Customers are concerned about safeguarding personal information and about agents running away with their money. Customers are more likely to use MM services if they trust service providers and agents-that is, if agents and mobile telecommunication companies can persuade customers that their personal information and money are safe. Furthermore, customers are more likely to use MM services if they can be sure that doing so is economical in terms of the time and money that must be expended.

Trust in the service provider reduces the anxiety and pressure that customers may experience when sending money via MM services. Again, the relationship between privacy risk and perceived risk can be attributed to customers' trust in the service providers, in this case, telecommunication service providers. Customers may trust network operators to protect their personal information, and as only limited personal details are given to agents for the purposes of an MM transaction, limited personal details may not be an issue for the customer. The non-significant relationship between service risk and perceived risk may reflect the fact that customers can communicate with service providers and obtain help when there is a problem with an MM transaction.

\section{Limitations and Directions for Future Studies}

All studies naturally confront some limitations. First, this study used only MM users without considering the views of non-users. The views of non-users of MM services may provide additional insights into the risk and trust issues in MM services. Future studies may also address certain methodological (or demographical) issues. For instance, the respondents here could all read and write, but as MM services are seen as a way of promoting financial inclusion (see PWC, 2016), future studies should focus on the rural poor and the uneducated. Another limitation of this study is that it did not explore how the perceived risk associated with MM services might be reduced, and future studies should address this issue. As Yang et al. (2015) noted, customers' trust evolves, so it is reasonable to look for ways to enhance customer trust in MM services over time. When customers trust MM service providers or MM service, the trust might influence their commitments to the MM service provider or MM service. Accordingly, MM service providers may consider building trust of their customers. 


\section{REFERENCE}

Aboobucker, I., \& Bao, Y. (2018). What obstruct customer acceptance of internet banking? Security and privacy, risk, trust and website usability and the role of moderators. The Journal of High Technology Management Research, 29(1), 109-123. doi:10.1016/j.hitech.2018.04.010

Ajzen, I. (1991). The theory of planned behavior. Organizational Behavior and Human Decision Processes, 50(2), 179-211. doi:10.1016/0749-5978(91)90020-T

Al-Gahtani, S. S. (2011). Modeling the electronic transactions acceptance using an extended technology acceptance model. Applied computing and informatics, 9(1), 47-77.

Bagozzi, R. P., \& Yi, Y. (1988). On the evaluation of structural equation models. Journal of the Academy of Marketing Science, 16(1), 74-94. doi:10.1007/BF02723327

Ball, J. G., Manika, D., \& Stout, P. (2016). Causes and consequences of trust in direct-to-consumer prescription drug advertising. International Journal of Advertising, 35(2), 216-247. doi:10.1080/02650487.2015.1009346

Bauer, H. H., Reichardt, T., Barnes, S. J., \& Neumann, M. M. (2005). Driving consumer acceptance of mobile marketing: A theoretical framework and empirical study. Journal of Electronic Commerce Research, 6(3), 181.

Boateng, H., Adam, D. R., Okoe, A. F., \& Anning-Dorson, T. (2016). Assessing the determinants of internet banking adoption intentions: A social cognitive theory perspective. Computers in Human Behavior, 65, 468-478. doi:10.1016/j.chb.2016.09.017

Carnevale, M., Loureiro, Y. K., \& Kabadayi, S. (2018). Customer Value Creation for Risky Products: The Role of Brand Trust and Trusting Beliefs. Journal of Creating Value.

Chai, S., \& Kim, M. (2010). What makes bloggers share knowledge? An investigation into the role of trust. International Journal of Information Management, 30(5), 408-415. doi:10.1016/j.ijinfomgt.2010.02.005

Chang, H. S., \& Hsiao, H. L. (2008). Examining the causal relationship among service recovery, perceived justice, perceived risk, and customer value in the hotel industry. Service Industries Journal, 28(4), 513-528. doi:10.1080/02642060801917646

Chauhan, S. (2015). Acceptance of mobile money by poor citizens of India: Integrating trust into the technology acceptance model. info, 17(3), 58-68.

Chin, W. W. (2010). How to write up and report PLS analyses. In Handbook of partial least squares (pp. 655-690). Springer. doi:10.1007/978-3-540-32827-8_29

Das, T. K., \& Teng, B. S. (2002). The dynamics of alliance conditions in the alliance development process. Journal of Management Studies, 39(5), 725-746. doi:10.1111/1467-6486.00006

Davis, F. D., Bagozzi, R. P., \& Warshaw, P. R. (1989). User acceptance of computer technology: A comparison of two theoretical models. Management Science, 35(8), 982-1003. doi:10.1287/mnsc.35.8.982

Diniz, E., Birochi, R., \& Pozzebon, M. (2012). Triggers and barriers to financial inclusion: The use of ICT-based branchless banking in an Amazon county. Electronic Commerce Research and Applications, 11(5), 484-494. doi:10.1016/j.elerap.2011.07.006

Donovan, K. (2012). Mobile money for financial inclusion. Information and Communications for development, 61(1), 61-73.

Featherman, M. S., \& Pavlou, P. A. (2003). Predicting e-services adoption: A perceived risk facets perspective. International Journal of Human-Computer Studies, 59(4), 451-474. doi:10.1016/S1071-5819(03)00111-3

Fishbein, M., \& Ajzen, I. (1975). Belief. Attitude, Intention, and Behavior: An Introduction to Theory and Research, 216.

Fornell, C., \& Larcker, D. F. (1981). Structural equation models with unobservable variables and measurement error: Algebra and statistics. JMR, Journal of Marketing Research, 18(3), 382-388. doi:10.2307/3150980

Gefen, D., Karahanna, E., \& Straub, D. W. (2003). Trust and TAM in online shopping: An integrated model. Management Information Systems Quarterly, 27(1), 51-90. doi:10.2307/30036519 
Gichuki, C. N., \& Mulu-Mutuku, M. (2018, April). Determinants of awareness and adoption of mobile money technologies: Evidence from women micro-entrepreneurs in Kenya. Women's Studies International Forum, 67, 18-22. doi:10.1016/j.wsif.2017.11.013

Hair, F. Jr, J., Sarstedt, M., Hopkins, L., \& G. Kuppelwieser, V. (2014). Partial least squares structural equation modeling (PLS-SEM) An emerging tool in business research. European Business Review, 26(2), $106-121$. doi:10.1108/EBR-10-2013-0128

Hille, P., Walsh, G., \& Cleveland, M. (2015). Consumer fear of online identity theft: Scale development and validation. Journal of Interactive Marketing, 30, 1-19. doi:10.1016/j.intmar.2014.10.001

Im, I., Kim, Y., \& Han, H. J. (2008). The effects of perceived risk and technology type on users' acceptance of technologies. Information \& Management, 45(1), 1-9. doi:10.1016/j.im.2007.03.005

Jang-Jaccard, J., \& Nepal, S. (2014). A survey of emerging threats in cybersecurity. Journal of Computer and System Sciences, 80(5), 973-993. doi:10.1016/j.jcss.2014.02.005

Kim, T. Y., Wang, J., \& Chen, J. (2018). Mutual trust between leader and subordinate and employee outcomes. Journal of Business Ethics, 149(4), 945-958. doi:10.1007/s10551-016-3093-y

Kim, Y., \& Peterson, R. A. (2017). A Meta-analysis of Online Trust Relationships in E-commerce. Journal of Interactive Marketing, 38, 44-54. doi:10.1016/j.intmar.2017.01.001

Kuisma, T., Laukkanen, T., \& Hiltunen, M. (2007). Mapping the reasons for resistance to Internet banking: A means-end approach. International Journal of Information Management, 27(2), 75-85. doi:10.1016/j. ijinfomgt.2006.08.006

Lee, J. E., \& Lemyre, L. (2009). A social-cognitive perspective of terrorism risk perception and individual response in Canada. Risk Analysis: An International Journal, 29(9), 1265-1280. doi:10.1111/j.1539-6924.2009.01264.x PMID:19650811

Liébana-Cabanillas, F., Nogueras, R., Herrera, L. J., \& Guillén, A. (2013). Analysing user trust in electronic banking using data mining methods. Expert Systems with Applications, 40(14), 5439-5447. doi:10.1016/j. eswa.2013.03.010

Lohmoeller, J. B. (1989). Latent variable path analysis with partial least squares. Heidelberg: Physica. doi:10.1007/978-3-642-52512-4

Lopez-Nicolas, C., \& Molina-Castillo, F. J. (2008). Customer Knowledge Management and E-commerce: The role of customer perceived risk. International Journal of Information Management, 28(2), 102-113. doi:10.1016/j. ijinfomgt.2007.09.001

Lu, Y., Yang, S., Chau, P. Y., \& Cao, Y. (2011). Dynamics between the trust transfer process and intention to use mobile payment services: A cross-environment perspective. Information \& Management, 48(8), $393-403$. doi:10.1016/j.im.2011.09.006

Malaquias, R. F., \& Hwang, Y. (2016). An empirical study on trust in mobile banking: A developing country perspective. Computers in Human Behavior, 54, 453-461. doi:10.1016/j.chb.2015.08.039

Martins, C., Oliveira, T., \& Popovič, A. (2014). Understanding the Internet banking adoption: A unified theory of acceptance and use of technology and perceived risk application. International Journal of Information Management, 34(1), 1-13. doi:10.1016/j.ijinfomgt.2013.06.002

Mothobi, O., \& Grzybowski, L. (2017). Infrastructure deficiencies and adoption of mobile money in Sub-Saharan Africa. Information Economics and Policy, 40, 71-79. doi:10.1016/j.infoecopol.2017.05.003

Namahoot, K. S., \& Laohavichien, T. (2018). Assessing the intentions to use internet banking: The role of perceived risk and trust as mediating factors. International Journal of Bank Marketing, 36(2), $256-276$. doi:10.1108/IJBM-11-2016-0159

Nofer, M. (2015). The value of social media for predicting stock returns: preconditions, instruments and performance analysis. Springer. doi:10.1007/978-3-658-09508-6 
Omwansa, T. K., Waema, T. M., Chen, C., \& Sullivan, N. P. (2013). The mobile phone as the tool to redefine savings for the poor: Evidence from Kenya. African Journal of Science, Technology. Innovation and Development, $5(5), 355-361$.

Ortiz, J., Chih, W. H., \& Tsai, F. S. (2018). Information privacy, consumer alienation, and lurking behavior in social networking sites. Computers in Human Behavior, 80, 143-157. doi:10.1016/j.chb.2017.11.005

Park, J., Lennon, S. J., \& Stoel, L. (2005). On-line product presentation: Effects on mood, perceived risk, and purchase intention. Psychology and Marketing, 22(9), 695-719. doi:10.1002/mar.20080

Pavlou, P. A., Liang, H., \& Xue, Y. (2007). Understanding and mitigating uncertainty in online exchange relationships: A principal-agent perspective. Management Information Systems Quarterly, 31(1), 105-136. doi: $10.2307 / 25148783$

PWC. (2016). 2016 Ghana Banking Survey: How to win in an era of mobile money. Retrieved from https://www. pwc.com/gh/en/assets/pdf/2016-banking-survey-report.pdf

Ratnasingam, P., Gefen, D., \& Pavlou, P. A. (2005). The role of facilitating conditions and institutional trust in electronic marketplaces. Journal of Electronic Commerce in Organizations, 3(3), 69-82. doi:10.4018/ jeco.2005070105

Ringle, C. M., Wende, S., \& Becker, J. M. (2015). SmartPLS 3. Boenningstedt: SmartPLS GmbH. Retrieved from http://www.smartpls.com

Rogers, E. M. (1995). Diffusion of Innovations: modifications of a model for telecommunications. In Die diffusion von innovationen in der telekommunikation (pp. 25-38). Springer. doi:10.1007/978-3-642-79868-9_2

Safeena, R., Kammani, A., \& Date, H. (2018). Exploratory Study of Internet Banking Technology Adoption. In Technology Adoption and Social Issues: Concepts, Methodologies, Tools, and Applications (pp. 333-355). Hershey, PA: IGI Global.

Shaikh, A. A., Glavee-Geo, R., \& Karjaluoto, H. (2018). How relevant are risk perceptions, effort, and performance expectancy in mobile banking adoption? International Journal of E-Business Research, 14(2), 39-60. doi:10.4018/IJEBR.2018040103

Song, J., \& Zahedi, F. (2002). A theoretical framework for the use of web infomediaries. In AMCIS 2002 Proceedings (p. 308).

Sum Chau, V., \& Ngai, L. W. (2010). The youth market for internet banking services: Perceptions, attitude, and behavior. Journal of Services Marketing, 24(1), 42-60. doi:10.1108/08876041011017880

Taylor, S., \& Todd, P. A. (1995). Understanding information technology usage: A test of competing models. Information Systems Research, 6(2), 144-176. doi:10.1287/isre.6.2.144

Tchouassi, G. (2012). Can Mobile Phones Really Work to Extend Banking Services to the Unbanked? Empirical Lessons from Selected Sub-Saharan Africa Countries. International Journal of Developmental Science, 1(2), $70-81$.

Tobbin, P., \& Kuwornu, J. K. (2011). Adoption of mobile money transfer technology: Structural equation modeling approach. European Journal of Business and Management, 3(7), 59-77.

Venkatesh, V., Morris, M. G., Davis, G. B., \& Davis, F. D. (2003). User acceptance of information technology: Toward a unified view. Management Information Systems Quarterly, 27(3), 425-478. doi:10.2307/30036540

Wu, Y. L., Tao, Y. H., \& Yang, P. C. (2008). The use of unified theory of acceptance and use of technology to confer the behavioral model of 3G mobile telecommunication users. Journal of Statistics and Management Systems, 11(5), 919-949. doi:10.1080/09720510.2008.10701351

Yang, Q., Pang, C., Liu, L., Yen, D. C., \& Tarn, J. M. (2015). Exploring consumer perceived risk and trust for online payments: An empirical study in China's younger generation. Computers in Human Behavior, 50, 9-24. doi:10.1016/j.chb.2015.03.058

Yousafzai, S. Y., Pallister, J. G., \& Foxall, G. R. (2003). A proposed model of e-trust for electronic banking. Technovation, 23(11), 847-860. doi:10.1016/S0166-4972(03)00130-5 


\section{APPENDIX A: MEASUREMENT INSTRUMENT}

Table 5. Measurement instrument

\begin{tabular}{|c|c|}
\hline Codes & Measurements items and sources \\
\hline & Economic risk (Yang et al., 2015; Featherman \& Pavlou, 2003) \\
\hline ERK1 & $\begin{array}{l}\text { I worry that mobile money transfer costs and other costs will make the total expenditure higher than } \\
\text { expected. }\end{array}$ \\
\hline ERK2 & I worry that if I want to send money, the mobile money vendor will collect the money but will not send it. \\
\hline \multirow[t]{2}{*}{ ERK3 } & I worry that monetary loss can be caused by the improper actions of mobile money vendors. \\
\hline & Functional risk (Yang et al., 2015; Featherman \& Pavlou, 2003) \\
\hline FRK1 & I worry that the limited functions of mobile money will not meet my requirements. \\
\hline FRK2 & I worry that I can't send money through the mobile money system because of unstable networks. \\
\hline \multirow[t]{2}{*}{ FRK3 } & $\begin{array}{l}\text { I worry that I can't send money through the mobile money system because of delays in transferring the } \\
\text { money. }\end{array}$ \\
\hline & Security risk (Yang et al., 2015; Featherman \& Pavlou, 2003) \\
\hline SRK1 & I worry that the transaction information will be stolen by a third party. \\
\hline SRK2 & I worry that my account information will be used by a third party to perform an illegal transaction. \\
\hline SRK3 & I worry that the money I send via mobile money can be withdrawn by a third party. \\
\hline \multirow[t]{2}{*}{ SRK4 } & I worry that the money I send through mobile money will not reach the intended recipient. \\
\hline & Privacy risk (Yang et al., 2015) \\
\hline PRK1 & $\begin{array}{l}\text { I worry that my personal information may be stolen during a transaction because of the carelessness of } \\
\text { mobile money vendors or service providers. }\end{array}$ \\
\hline PRK2 & $\begin{array}{l}\text { I worry that my personal information can be improperly collected and used by mobile money vendors and } \\
\text { mobile money service providers. }\end{array}$ \\
\hline \multirow[t]{2}{*}{ PRK3 } & $\begin{array}{l}\text { I worry that hackers can steal my personal information from the database of the mobile money service } \\
\text { provider. }\end{array}$ \\
\hline & Time risk (Yang et al., 2015) \\
\hline TMK1 & I worry that it will cost me a lot of time to perform mobile money transactions. \\
\hline TMK2 & I worry that it will cost me a lot of time to access mobile money services. \\
\hline \multirow[t]{2}{*}{ TMK3 } & I worry that it will cost me a lot of time to confirm my ID and other details for mobile money transactions. \\
\hline & Service risk (Yang et al., 2015; Featherman \& Pavlou, 2003) \\
\hline SK1 & $\begin{array}{l}\text { I worry that if I perform a mobile money transaction, it will be difficult to communicate with the mobile } \\
\text { money service provider or vendor when I need help. }\end{array}$ \\
\hline SK2 & $\begin{array}{l}\text { I worry that if I perform a mobile money transaction, it will be difficult to get the mobile money service } \\
\text { provider or vendor to respond to my queries. }\end{array}$ \\
\hline \multirow[t]{2}{*}{ SK3 } & $\begin{array}{l}\text { I worry that if I perform a mobile money transaction, it will be difficult to know where mobile money } \\
\text { vendors are located. }\end{array}$ \\
\hline & Psychological risk (Yang et al., 2015; Featherman \& Pavlou, 2003) \\
\hline PK1 & I worry that I will experience stress if there is a loss during a mobile money transaction. \\
\hline PK2 & $\begin{array}{l}\text { I worry that I will be anxious before the mobile money transaction is confirmed and reaches the intended } \\
\text { recipient. }\end{array}$ \\
\hline PK3 & I worry that I will be anxious if the money can't be transferred in a timely way. \\
\hline
\end{tabular}


Table 5.

\begin{tabular}{|l|l|}
\hline \multicolumn{1}{|c|}{ Codes } & \multicolumn{1}{c|}{ Measurements items and sources } \\
\hline & Social risk (Yang et al., 2015; Featherman \& Pavlou, 2003) \\
\hline SKk1 & $\begin{array}{l}\text { I worry that if I am cheated when making an online payment, my friends and family will make negative } \\
\text { comments about me. }\end{array}$ \\
\hline SKk2 & I worry that if I don't use mobile money services, my friends and family will think I'm not fashionable. \\
\hline SKk3 & I worry that my friends and family will laugh at me for using mobile money services. \\
\hline & Economy-based trust (Chai \& Kim, 2010) \\
\hline ET1 & Using mobile money services saves time. \\
\hline ET2 & Using mobile money service saves cost. \\
\hline ET3 & It is economical to use mobile money services. \\
\hline & Trust in service providers (Chai \& Kim, 2010) \\
\hline TP1 & I trust that mobile money service providers will safeguard my personal information. \\
\hline TP2 & I trust that mobile money service providers will safeguard my money. \\
\hline TP3 & I trust that mobile money agents will not run away with my money. \\
\hline & Intentions to use mobile money services (Yang et al., 2015). \\
\hline IUM1 & In general, I'm willing to use mobile money services. \\
\hline IUM2 & If possible, I will continue to use mobile money services. \\
\hline IUM3 & I will encourage my family and friends to use mobile money services. \\
\hline
\end{tabular}

Ibn Kailan is a PhD Candidate at the University of Ghana and a faculty at the University of Professional Studies, Accra. His research interested are in marketing, sustainability marketing, market orientation, mobile commerce, corporate social responsibility, and emerging market research.

Shaikh is a faculty at the Jyväskylä University School of Business and Economics.

Henry Boateng holds a PhD in Knowledge Management from the University of Technology, Sydney. His research experience covers knowledge management, branding, electronic business and commerce and internet application in marketing. Email: hboateng85@gmail.com

Robert E. Hinson is Professor in the University of Ghana Business School, Legon, Ghana and a Research Associate at the University of the Free State Business School in South Africa. Email contact: rhinson@ug.edu.gh 